\title{
A Survey of Selected Grey Forecasting Models with Application to Medical Tourism Forecasting
}

\author{
Althea Dianne La Foucade, Samuel Gabriel, Ewan Scott, Karl Theodore, Charmaine Metivier* \\ The University of the West Indies, HEU, Centre for Health Economics, St. Augustine, Trinidad and Tobago \\ Email: *charmaine.metivier@sta.uwi.edu
}

How to cite this paper: La Foucade, A.D., Gabriel, S., Scott, E., Theodore, K. and Metivier, C. (2019) A Survey of Selected Grey Forecasting Models with Application to Medical Tourism Forecasting. Theoretical Economics Letters, 9, 1079-1092. https://doi.org/10.4236/tel.2019.94070

Received: January 14, 2019

Accepted: April 23, 2019

Published: April 26, 2019

Copyright ( 2019 by author(s) and Scientific Research Publishing Inc. This work is licensed under the Creative Commons Attribution International License (CC BY 4.0).

http://creativecommons.org/licenses/by/4.0/

\begin{abstract}
This paper examines the predictive capacity of two Grey Systems Forecasting models. The original Grey $\operatorname{GM}(1,1)$ Forecasting model, introduced by Deng [1] [2] together with an improved Grey GM(1,1) model proposed by Ji et al. [3] are used to forecast medical tourism demand for Bermuda. The paper also introduces a quasi-optimization method for the optimization of the alpha (weight) parameter. Five steps ahead out-of-sample forecasts are produced after estimating the models using four data points. The results indicate that the optimization of the alpha parameter substantially improves the predictive accuracy of the models; reducing the five steps ahead out-of-sample Mean Absolute Percentage Error from roughly $7 \%$ to roughly 3.80\% across the two models. Largely, the forecasting approaches demonstrate significant potential for use as an alternative to the traditional forecasting methods in circumstances where substantial amounts of high-quality data are not available.
\end{abstract}

\section{Keywords}

Medical Tourism, Medical Tourism Demand, Grey Forecasting and Parameter Optimization

\section{Introduction}

With the massive increase in the availability of information, communication and medical technology, combined with major advances in trade relations and expanded patient mobility inter alia [4] [5] [6], there has emerged a new and embryonic pattern of consumption of medical services. This pattern of consumption of medical services involves patients crossing national, regional and international frontiers as they seek to fulfil specific and general health needs. Natu- 
rally, the pattern of production of these health services has also evolved and continues to evolve in response to the demand signals. Admittedly, the literature is void of any definitive estimates of the true size and prevailing trend of the international medical tourism market and even more so for the Caribbean segment of that market. This is said to be the result of "inconsistencies in defining medical travel and a lack of verifiable data at the country levep'. However, a recent Patients Beyond Borders report estimates the global medical tourism market to be in the vicinity of USD 45.5 - 72 billion, fuelled by some 14 million cross-border patients, with an average outlay of USD 3800 - 6000 per visit [7].

Indeed, the shifting paradigm in the health services/consumption relationship should not be underestimated. For many decades, the flow of medical tourists was almost completely unidirectional whereby affluent third world patients would travel to the countries of the developed world to access medical care that was not available at home or was believed to be of inferior quality. Today, there is substantial evidence of what some refer to as "reverse globalization"; an increasing number of first world patients who are making their way to developing countries to access health services. Caribbean countries are eager to capitalize on the opportunity presented by this new paradigm. To adequately do so, however, prudent planning for the infrastructural, accommodation and transportation service needs, supported by reliable data, is paramount. The ability to accurately anticipate the demand for the services and the identification of the appropriate methods for achieving this end, given the novel nature of the practice and inherent data scarcity, are critical.

\section{Literature Review}

While the exact nature of the practice is largely understood, the literature lacks harmony with regards to its precise name. Referring to this new configuration of health services consumption and production, terms such as "wellness tourism" [8], "health tourism" [9] and "medical tourism" [4] [10] [11] [12] have been coined. These terms, although sometimes used interchangeably, often describe different concepts [13]. Mueller and Kaufmann 2001 [8] lay claim to one of the most referenced designations of the practice, "wellness tourism". In their assessment, "Wellness tourism is the sum of all the relationships and phenomena resulting from a journey and residence by people whose main motive is to preserve or promote their health...". Health tourism, on the other hand, is often seen as encompassing both medical tourism and wellness tourism and is defined as, "the organized travel outside local environment for the maintenance, enhancement or restoration of an individuals wellbeing in mind and body" [9]. Meanwhile, Lunt and others explained the notion of medical tourism as "... when consumers elect to travel across international borders with the intention of receiving some form of medical treatment" [4]. The term "medical tourism" embodies the idea of the commercialization of a practice that has actually been in existence for many centuries. It was noted that "In the eighteenth century, for 
example, British patients visited spas because they were places with supposedly health-giving mineral waters, treating diseases from gout to liver disorders and bronchitis" [14]. Irrespective of the term used to describe the phenomenon, the estimation of demand for this now commercialized service has often proved challenging.

The literature is sketchy at best regarding the forecasting of the demand for medical tourism. However, there is a vast amount of published works on the forecasting and modelling of the demand for traditional tourism. Song and others [10] [15] documented some 121 publications between 2000 and 2007, while Song and Witt [16] and Li and others [17] reviewed over 420 articles published between 1960 and 2002. The authors noted that the forecasting models produced results of varying degrees of accuracy. This they attributed to several factors including data frequency, the length of the forecast horizon and the estimation method employed. Indeed, methods of forecasting tourism demand encompass a wide spectrum. These include the time series approaches of ARIMA and Multivariate ARIMA [18] [19] [20] and the traditional econometric methods of Error Correction models [21] [22] [23], Almost Ideal Demand Systems and Linear Almost Ideal Demand Systems [24] [25] [26]. Meanwhile, researchers [27] [28] [29] in the Caribbean region have sought insight into the nature of tourism demand through the use of Generalized Least Squares; Panel Autoregressive Distributive Lag approach and Augmented Gravity models.

Nevertheless, all of the above approaches are beset by the same restriction, in that they generally demand a significant amount of detailed, high-quality data that are usually expected to adhere to some specific distributional assumption. Grey Systems Theory and specifically Grey Forecasting models, however, focus on solving problems that are characterized by small samples and poor information, characteristics that are common with data on medical tourism.

Indeed, the Grey Systems family of forecasting models have been successfully applied across many fields. The forecasting of demand for medical tourism and its various configurations is one such area. Researchers in Thailand have successfully applied Grey $\operatorname{GM}(1,1)$ forecasting model to estimate demand for Thailand's medical tourism product and the related revenues [30]. Other areas where Grey approaches have been put to use include the electronics industry [31] [32] [33], the energy industry [34] [35] [36], the financial sector [37] [38] [39] and the medical field [40] [41], among a host of others.

Moreover, many authors [42] [43] [44] [45] have pointed out that there may be instances when enhancements to the predictive accuracy of the model may be realized. Accordingly, this can be achieved through a range of options. Nguyen and Tran [46] combined the traditional Grey model, Data Envelopment Analysis and Neural Networks in their attempt to improve the forecasting accuracy of electricity in India. The approach produced an overall Mean Absolute Percentage Error (MAPE) of 7.05\%. Meanwhile, Thành [47], in examining Vietnam's tourism industry, was able to reduce the out-of-sample MAPE of $9.04 \%$ produced using the classical Grey to $6.90 \%$ by applying a Modified Fourier Residual 
Modification to a Nonlinear-Grey Bernoulli model. D. C. Li, Yeh, and Chang [48] attained some degree of success by applying the Trend and Potency Tracking Method developed by Der Chang Li and Yeh [49] to the Grey GM(1,1) model to develop what he termed an "adaptive" Grey forecasting model. Here, he was able to improve forecasting accuracy by between $5.8 \%$ and $17 \%$ when compared to the forecasts of the original Grey model.

What is more, as part of the overall effort to improve the Grey forecasting accuracy, others have sought to identify an optimal generation coefficient "alpha $(\alpha)$ ", for the original Grey GM(1,1) model. The optimization of the $\alpha$ parameter has been achieved through many diverse approaches. One common method is the genetic algorithm which has been applied by C. H. Wang and Hsu [45] to forecast high technology industrial output and by $\mathrm{Hu}$ and others [50] in a more elaborate Neural Network/Grey-Markov model, used in tourism demand forecasting. C. H. Wang and Hsu's approach produced four-period out-of-sample MAPE of 5.01\%, while the approach of $\mathrm{Hu}$ and others resulted in MAPE ranging from $0.03 \%$ to $39.7 \%$ in "Case 1 " and from $0.22 \%$ to $17.54 \%$ in "Case 2". Moreover, the fairly recent approach of Swarm Intelligence Algorithms, specifically those of Particle Swarm Optimization (PSO) [44] [51] and Artificial Fish Swarm Optimization [52], have also been put to use in enhancing the predictive accuracy of Grey models. Ma et al.'s [44] use of the PSO algorithm to optimize the alpha parameter of the GM(1,1) model (PSO-GM(1,1)) yielded marginal forecasting improvements. In their forecasts of underground pressure for working surface, the out-of-sample MAPE of the original $\operatorname{GM}(1,1)$ model fell from $3.405 \%$ to $3.179 \%$ using the PSO-GM $(1,1)$ model. Similar forecasting improvements have been recorded by Lin et al.'s use of Artificial Fish Swarm Optimization Algorithm in conjunction with Grey GM(1,1) model (AFSA-GM(1,1)). In their case, the MAPE fell from $14.31 \%$, in the case of the GM(1,1) to $9.71 \%$ when the AFSA-GM $(1,1)$ model was used.

\section{Methodology}

Proposed by Julong Deng in 1989 [1], Grey Forecasting models are often used in circumstances where limited data are available and uncertainty prevails. A key feature of the medical tourism market in the Caribbean region is its relative novelty. This presents several challenges, chief of which are demand uncertainty and limited availability of high-quality, sufficiently large demand datasets. These are features that make the Grey systems forecasting model most suitable for medical tourism forecasting in Bermuda. Unlike the traditional forecasting methods, which address uncertainty by the use of large samples that adhere to some specific distributional assumption, Grey systems theory centres on solving problems in cases where data are minimal and are of poor quality; characteristics that will prove difficult for approaches of probability and statistics to manage [53]. According to Chin-tsai and others [30] “...production forecasting depends more on limited current data rather than large amounts of historical data". In fact, 
they submit that with the use of these models, unknown systems can be characterized with as little as four data points.

The GM(1,1) forecasting model is the basic and most popular of the family of Grey prediction models. According to Yan et al. [54], the model creates a first-order accumulation production for a series $x^{(0)}=\left[x^{(0)}(k) \mid k=1,2, \cdots, n\right] \mid n \geq 4$. Through the application of the Accumulated Generating Operation (1-AGO) to $x^{(0)}$, a new, more regular series, $x^{(1)}=\left[x^{(1)}(k) \mid k=1,2, \cdots, n\right]$ is created. It is a single variable (1) first order (1) Grey model and hence the term $\operatorname{GM}(1,1)$. A new series $z^{(1)}(k)=\left\{\alpha x^{(1)}(k)+\alpha x^{(1)}(k-1), k=2,3, \cdots, n\right\}$ is produced from $x^{(1)}$ through the application of near neighbour means. The generation coefficient or weight, $\alpha$, is such that $0<\alpha<1$, which is set a 0.5 in the original Grey model. Grey model uses the Grey difference equation of $\mathrm{GM}(1,1)$, $x^{(0)}(k)+a z^{(1)}(k)=b$, where $a$ and $b$ are the development coefficient and the Grey action quantity, respectively. These parameters can be estimated via Ordinary Least Squares (OLS) and the difference equation solved. The one-time Inverse Accumulating Generation Operator (1-IAGO) is applied to the solution for the difference equation whereby forecast values, $\hat{x}^{(0)}(k+1)$, are produced.

\section{Assessment of Model Performance}

The model's performance can be assessed by two main measures, the Absolute Percentage Error (APE) and the MAPE, which are calculated as follows:

$$
\begin{gathered}
\mathrm{APE}=\frac{\left|x^{(0)}(k)-\hat{x}^{(0)}(k)\right|}{x^{(0)}(k)} \times 100 . \\
\mathrm{MAPE}=\frac{1}{n-1} \sum_{k=2}^{n} \frac{\left|x^{(0)}(k)-\hat{x}^{(0)}(k)\right|}{x^{(0)}(k)} \times 100 .
\end{gathered}
$$

Tsai [55] outlined, as seen in Table 1, the evaluation criteria for the model on the basis of the MAPE.

\section{Properties of the Grey GM(1,1) Model and Modifications}

While the original Grey $\operatorname{GM}(1,1)$ forecasting model has had some degree of success in forecasting, Ji et al. [3] demonstrated that the model is biased as follows:

Table 1. MAPE criteria for model evaluation.

$$
\text { Residual Test: MAPE }=\frac{1}{n-1} \sum_{k=2}^{n} \frac{|\epsilon(k)|}{x^{(0)}(k)} \times 100
$$

\begin{tabular}{cc}
\hline Criteria (MAPE) & Interpretation \\
\hline$<10 \%$ & High forecasting accuracy \\
$10 \%-20 \%$ & Good forecasting accuracy \\
$20 \%-50 \%$ & Reasonable forecasting accuracy \\
$>50 \%$ & Weak and inaccurate predictability \\
\hline
\end{tabular}


It is known that the Grey $\mathrm{GM}(1,1)$ forecasting model is an exponential model, therefore if an exponential system, $x(t)=A \mathrm{e}^{a t}$, is assumed and is in a discrete form as:

$$
x^{(0)}(k)=A \mathrm{e}^{a(k-1)}, k=1,2, \cdots, N
$$

If the first $N$ item is considered as a series of raw data, then the first order accumulation generation is given by:

$$
x^{(1)}(k)=A \frac{1-\mathrm{e}^{a k}}{1-\mathrm{e}^{a}}, k=1,2, \cdots, N
$$

Then setting up GM(1,1) model will look like:

$$
\left[\begin{array}{cc}
-\frac{1}{2} A \frac{2-\mathrm{e}^{a}-\mathrm{e}^{2 a}}{1-\mathrm{e}^{a}} & 1 \\
-\frac{1}{2} A \frac{2-\mathrm{e}^{2 a}-\mathrm{e}^{3 a}}{1-\mathrm{e}^{a}} & 1 \\
\vdots & \vdots \\
-\frac{1}{2} A \frac{2-\mathrm{e}^{(N-1) a}-\mathrm{e}^{N a}}{1-\mathrm{e}^{a}} & 1
\end{array}\right], Y_{N}=\left[\begin{array}{c}
x^{(0)}(2) \\
x^{(0)}(3) \\
\vdots \\
x^{(0)}(N)
\end{array}\right]
$$

Therefore:

$$
\left[\begin{array}{l}
\hat{a} \\
\hat{b}
\end{array}\right]=\left(B^{\mathrm{T}} B\right)^{-1} B^{\mathrm{T}} Y_{N}=\left[\begin{array}{c}
\frac{2\left(1-\mathrm{e}^{a}\right)}{1+\mathrm{e}^{a}} \\
\frac{2 A}{1+\mathrm{e}^{a}}
\end{array}\right]
$$

From the above, the following can be derived:

$$
\hat{x}^{(1)}(k)=\frac{-A \mathrm{e}^{a}}{1-\mathrm{e}^{a}} \mathrm{e}^{-\hat{a}(k-1)}+\frac{A}{1-\mathrm{e}^{a}}, k=2,3, \cdots, N
$$

Furthermore, the fitting results are as follows:

$$
\begin{gathered}
\hat{x}^{(0)}(1)=A \\
\hat{x}^{(0)}(k)=\frac{-A \mathrm{e}^{a}\left(1-\mathrm{e}^{\hat{a}}\right)}{1-\mathrm{e}^{a}} \mathrm{e}^{-\hat{a}(k-1)}, k=2,3, \cdots, N
\end{gathered}
$$

If it is assumed that:

$$
a^{\prime}=-\hat{a}, K=\frac{-\mathrm{e}^{a}\left(1-\mathrm{e}^{\hat{a}}\right)}{1-\mathrm{e}^{a}},
$$

Then formula (6) can be expressed as:

$$
\hat{x}^{(0)}(k)=K A \mathrm{e}^{a^{\prime}(k-1)}, k=2,3, \cdots, N
$$

Formula (7) combined with formula (5) is not identical to formula (1), indicating that the $\operatorname{GM}(1,1)$ model is biased.

In response to this, Ji and others [3] went on to outline an improved version of the $\operatorname{GM}(1,1)$ termed the Unbiased $\operatorname{GM}(1,1)$ model $\operatorname{UGM}(1,1))$ and is defined as follows: 
Formula (5) may be rewritten as, $\left[\begin{array}{c}\frac{2\left(1-\mathrm{e}^{a}\right)}{1+\mathrm{e}^{a}} \\ \frac{2 A}{1+\mathrm{e}^{a}}\end{array}\right]$ wherefrom the following can be derived:

$$
a=\ln \frac{2-\hat{a}}{2+\hat{a}}, A=\frac{2 \hat{b}}{2+\hat{a}}
$$

where $\hat{a}$ and $\hat{b}$ are the parameters that were determined via the OLS of $a$ and $A$, the unbiased $\mathrm{GM}(1,1)$ model is established as follows:

$$
\hat{x}^{(0)}(k)=A^{\prime} \mathrm{e}^{a^{\prime}(k-1)}, k=2,3, \cdots \text { and } \hat{x}^{(0)}(1)=x^{(0)}(1)
$$

According to the authors, this modification lacks the "inherent deviation" present in $\operatorname{GM}(1,1)$ model and therefore "eliminates the invalid phenomenon which happens in establishing $G M(1,1)$ model when the raw data sequence grows fast" [3]. The result is a more accurate forecasting model with broader applicability.

While these alterations may have added value to the original $\operatorname{GM}(1,1)$ model, more noteworthy enhancements to the predictive accuracy of the model can be realized. This can be achieved if the optimal value for the generation coefficient $\alpha$ can be identified and utilized. Explicitly, when the OLS process results in a sizeable value for the development coefficient $a$, setting $\alpha$ equal to 0.5 may result in sub-optimal forecasting results [44]. In such instances, the optimization of the $\alpha$ parameter often leads to improved forecasting accuracy.

\section{A Quasi-Optimization Method}

The Grey models' predictive accuracy improvements will be achieved through the identification of the optimal value of the $\alpha$. To this end, the following method is proposed.

The optimized parameter $\alpha$, is the value that is associated with the smallest in-sample MAPE, in other words, the objective is to identify the $\alpha$ that minimizes the following function:

$$
\min \mathrm{MAPE}=\frac{1}{n-1} \sum_{k=2}^{n}|P E(k)|=\frac{1}{n-1} \sum_{k=2}^{n}\left|\frac{\hat{x}^{(0)}(k)-x^{(0)}(k)}{x^{(0)}(k)}\right| \times 100
$$

We know that $0<\alpha<1$ therefore, this approach initializes by the generation of values for alpha within the feasible range, specifically alphas within the range $0.01<\alpha<0.99999$. An initial value of 0.01 is generated and successive values are created by incrementing by 0.00001 up to 0.99999 . The algorithm then iterates $n^{1}$ times, entering each of the generated alphas into the Grey forecasting model and generates $n$ MAPE values. A plot of the MAPEs and the generated alphas is then created yielding, with the aid of the MATLAB's "min" function, the value of alpha that produces the lowest MAPE and thus identifies the general ${ }^{1} n$, in this case, is the number of generated alphas between 0.01 and 0.99999 . 
region where a more exact quasi-optimal value is located. After this has been accomplished, a second round of alpha generation is carried out. In this instance, the incremental value, the upper and lower bounds are reduced to closely border the initial quasi-optimal alpha identified in the first round. This creates a zooming effect that detects a quasi-optimal alpha that is more precise, while reducing the need for a lengthy iterative process. A graphical depiction of this technique of parameter optimization is demonstrated in Figure 1 below.

\section{Results}

Unlike other destinations in the region which has an entire facility dedicated to medical tourists, in Bermuda the Hospitals Board's Pathology department targets international patients and is one of only a handful of facilities in the Caribbean to have received JCI accreditation. This facility represents the main medical tourism facility on the island and indicates the medical tourism sector in Bermuda is very much in its infancy stage. Other medical tourism facilities in the region include Doctors Hospital in the Bahamas; the Barbados Fertility Centre, with branches in Barbados and Trinidad; Health City Cayman Islands; and Crossroads Centre in Antigua.

The data used in this study spanned 2004 to 2012, with these being the latest available data. The data were sub-divided into inpatient and outpatient visits ${ }^{2}$. Bermuda saw an annual average of 1419 medical tourists between 2004 and 2012. The first four data points were used to estimate the models and the last five served as the holdout sample to allow for out-of-sample validation. The figures of total "medical tourists", likely to have been underestimated as patients so classified, may have received care from other facilities from which data were not collected. All analyses were conducted in MATLAB version R2015a.

As can be seen from Figure 2, the graph exhibits a clear trend showing a general decline in medical tourists visiting Bermuda over the period 2004 to 2012. Despite the general trend, substantial fluctuations in the figures can be observed during the periods 2006 to 2007 and 2010 to 2012. Moreover, the analysis was executed with the generation of 9900 initial set alpha values. Once the initial quasi-optimal alpha was identified, the upper and lower limits were reduced.

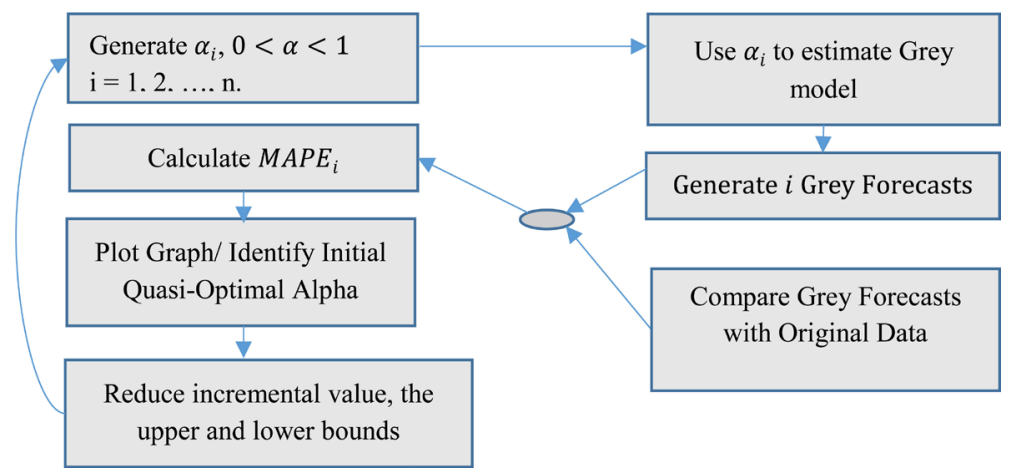

Figure 1. Quasi-Optimization Process (Diagram adapted from Ma et al. [44]).

${ }^{2}$ The figures were consolidated for the analysis. 
This modification lead to the generation of 300,001 alphas (potential solutions), to be used in the second round of analyses, where in-sample MAPE, five periods ahead out-of-sample forecasts, plots and out-of-sample MAPE were produced and the quasi-optimal alpha identified.

Table 2 shows results obtained from the original Grey GM(1,1) model and the

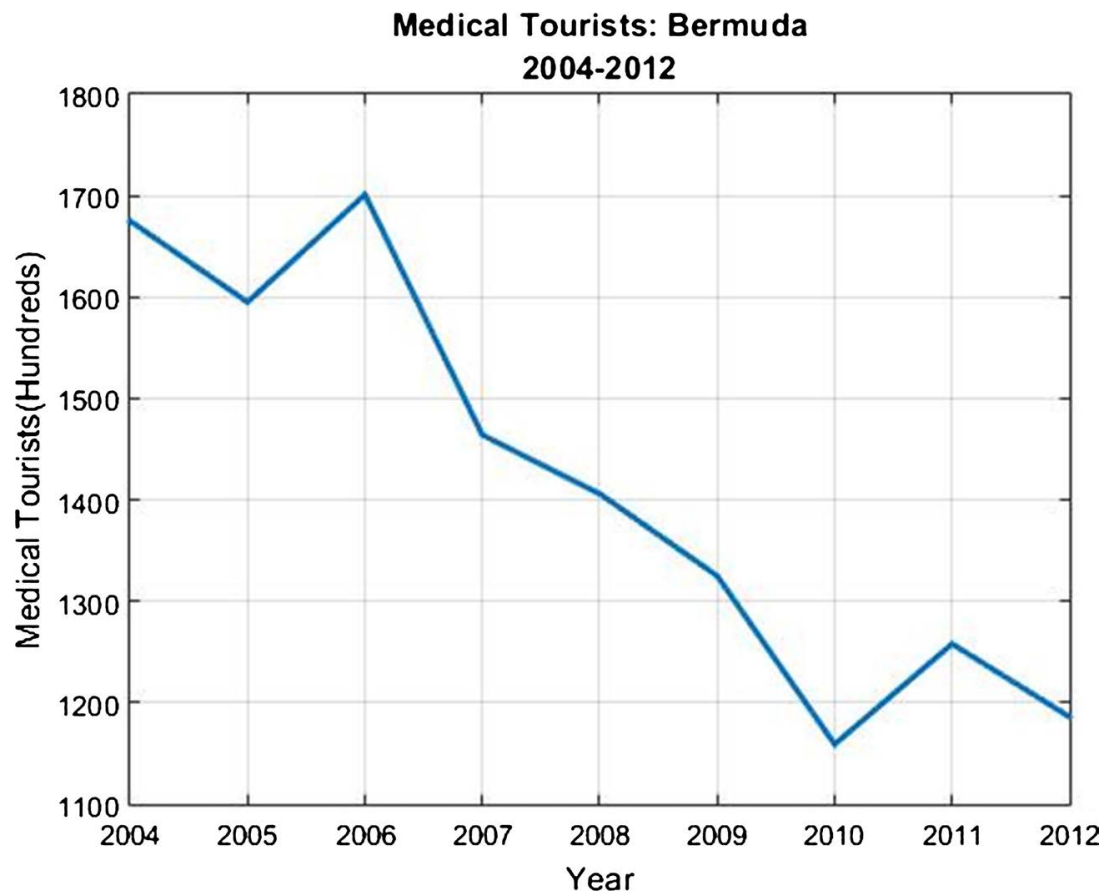

Figure 2. Trend of Medical Tourists Visiting Bermuda (2004-2012).

Table 2. APE, Standard and Optimal Alphas: $\operatorname{GM}(1,1)$ Model and $\operatorname{UGM}(1,1)$.

\begin{tabular}{ccccccc}
\hline & \multicolumn{2}{c}{ GM(1,1) Model } & & UGM(1,1) Model & \\
\cline { 2 - 6 } & \multicolumn{2}{c}{$\alpha$ values } & $\begin{array}{c}\text { Percent } \\
\text { Improvement }\end{array}$ & \multicolumn{2}{c}{$\alpha$ values } & $\begin{array}{c}\text { Percent } \\
\text { Improvement }\end{array}$ \\
Year & $\mathbf{0 . 5}$ & $\mathbf{0 . 3 8 8 4 0 3}$ & & 0.5 & $\mathbf{0 . 3 9 0 0 8 1}$ & \\
2004 & - & - & - & - & - & - \\
2005 & 3.456 & 1.70 & 51 & 3.37 & 1.66 & 51 \\
2006 & 6.779 & 9.41 & 39 & 6.86 & 9.42 & 37 \\
2007 & 4.083 & 0.00 & 100 & 4.00 & 0.00 & 100 \\
I.S. MAPE & 4.773 & 3.70 & 22 & 4.74 & 3.69 & 22 \\
& & & Out-of-Sample Forecasts & & \\
2008 & 4.15 & 1.08 & 74 & 4.06 & 1.06 & 74 \\
2009 & 6.20 & 0.28 & 95 & 6.11 & 0.24 & 96 \\
2010 & 16.67 & 8.31 & 50 & 16.57 & 8.38 & 49 \\
2011 & 3.29 & 5.20 & -58 & 3.20 & 5.12 & -60 \\
2012 & 5.28 & 4.47 & 15 & 5.19 & 4.37 & 16 \\
O.S. MAPE & 7.12 & 3.87 & 46 & 7.02 & 3.83 & 45 \\
\hline
\end{tabular}


Unbiased Grey GM(1,1) model, as well as in-sample and out-of-sample APE, MAPE and the percentage improvement over the suboptimal Grey models. As shown, the in-sample APE for both models ranged from $0.0 \%$ to $9.41 \%$. In-sample MAPE are all below 5\%, fluctuating from $3.69 \%$ to $4.78 \%$ across both models. The unbiased versions of the $\operatorname{GM}(1,1)$ model slightly outperformed the original model. The results also show that the optimization of the alpha parameter significantly improved the performance of both models, with the out-of-sample MAPE falling from $7.12 \%$ and $7.02 \%$ to $3.87 \%$ and $3.83 \%$ for the standard $\operatorname{GM}(1,1)$ and the unbiased $\operatorname{GM}(1,1)$ models, respectively.

With reference to the evaluation criteria delineated in Table 1 , both models demonstrated "high forecasting accuracy". However, the optimized models demonstrated substantially improved levels of accuracy over the standard versions.

\section{Discussion and Conclusions}

As the Caribbean region contemplates entering the medical tourism market in a meaningful way, there is a clear need for a reliable mechanism through which demands for the product may be gauged. This capability will prove invaluable to planners, investors and policy-makers. While the conventional means of producing these forecasts have been primarily through econometric and other time series models, the novel nature of this product and the accompanying scarcity of lengthy data series have deemed these approaches unsuitable for the task. This paper has demonstrated the Grey models' ability to overcome these challenges by producing accurate forecasts of medical tourism demand in Bermuda.

Furthermore, as outlined above, there are many ways of improving the efficiency of the Grey GM(1,1) model. However, for the most part, these approaches have been implemented using complex optimization methods that require advanced programming capabilities, sometimes mathematical skills and substantial amounts of data, which are often a primary hindrance to medical tourism forecasting in Bermuda and in the Caribbean region in general. The very nature of these approaches renders them unusable to most technocrats and the average investor. By contrast, the approach outlined in this paper uses a relatively simple and intuitive parameter optimization strategy, one that as far as we are aware, has not been previously used. The "highly accurate" results generated using the minimum of four historical data points also reveal the "data leanness" of the overall model. Furthermore, the forecasting accuracy as demonstrated by the results is more than comparable and, in many cases, superior to those produced by the more demanding models and optimization strategies. Indeed, the strength of this optimization method lies in its comparative simplicity and precision.

An implication of the results resides in the fact that the data relating to the medical tourism industry are extensively scarce. Therefore, by demonstrating that accurate forecasts of the demand for medical tourism product in Bermuda can nevertheless be produced and thereby provide critical evidence for deci- 
sion-making, a potential solution to the data challenge is presented. Furthermore, the relative simplicity in operationalizing the forecast model provides the opportunity for the average technocrat and business decision-maker to model medical tourism forecasts without the need for advanced modelling capabilities and with a minimal amount of data.

Additionally, the experienced downturn in medical tourism demand indicates a need for the Bermudian authorities to make the necessary adjustments to the medical tourism product offering, including the possible establishment of a facility dedicated to meeting the health needs of international patients much like the country's regional neighbours have done. An improved marketing strategy may also be needed while attention must also be directed to consumer experience and quality of service. Failure to reverse this trend may result in the forfeiting of the potentially significant economic benefits that this emerging industry promises.

\section{Conflicts of Interests}

The authors declare no conflicts of interest regarding the publication of this paper.

\section{References}

[1] Deng, J. (1989) Introduction to Grey System Theory. Journal of Grey System, 1, $1-24$.

[2] Liu, S. and Lin, Y. (2006) Grey Information Theory and Practical Applications. Springer-Verlag, London, Xii, 508.

[3] Ji, P.R., Huang, Q. and Zou, W. (2012) UGM $(1,1)$ Model and Its Application to Electric Load Forecasting. Advanced Materials Research, 461, 493-496. https://doi.org/10.4028/www.scientific.net/AMR.461.493

[4] Lunt, N., Smith, R., Exworthy, M., Green, S.T., Horsfall, D. and Mannion, R. (2011) Medical Tourism: Treatments, Markets and Health System Implications: A Scoping Review.

[5] Timmermans, K. (2004) Developing Countries and Trade in Health Services: Which Way Is Forward? International Journal of Health Services, 34, 453-466. https://doi.org/10.2190/323D-0VJ3-XC58-VXHU

[6] Gill, H. and Singh, N. (2011) Exploring the Factors That Affect the Choice of Destination for Medical Tourism. Journal of Service Science and Management, 4, 315-324. https://doi.org/10.4236/jssm.2011.43037

[7] Patients beyond Borders (2016) Medical Tourism Statistics \& Facts. http://www.patientsbeyondborders.com/medical-tourism-statistics-facts

[8] Mueller, H. and Kaufmann, E. (2001) Wellness Tourism: Market Analysis of a Special Health Tourism Segment and Implications for the Hotel Industry. Journal of Vacation Marketing, 7, 5-17.

[9] Carrera, P.M. and Bridges, J.F. (2006) Globalization and Healthcare: Understanding Health and Medical Tourism. Expert Review of Pharmacoeconomics \& Outcomes Research, 6, 447-454. https://doi.org/10.1586/14737167.6.4.447

[10] Stolk, M. (2009) Sun, Sea, Sand, Safari and Surgery: A Research Study to Investigate the Medical Tourism Industry in South Africa. 1-139. 
[11] Mathers, C.D. and Loncar, D. (2006) Projections of Global Mortality and Burden of Disease from 2002 to 2030. PLOS Medicine, 3, 2011-2030. https://doi.org/10.1371/journal.pmed.0030442

[12] Vijaya, R.M. (2010) Medical Tourism: Revenue Generation or International Transfer of Healthcare Problems? Journal of Economic Issues, 44, 53-70. https://doi.org/10.2753/JEI0021-3624440103

[13] Voigt, C., Brown, G. and Howat, G. (2011) Wellness Tourists: In Search of Transformation. Tourism Review, 66, 16-30. https://doi.org/10.1108/16605371111127206

[14] Singh, N. (2013) Exploring the Factors Influencing the Travel Motivations of US Medical Tourists. Current Issues in Tourism, 16, 436-454. https://doi.org/10.1080/13683500.2012.695341

[15] Song, H. and Li, G. (2008) Tourism Demand Modelling and Forecasting-A Review of Recent Research. Tourism Management, 29, 203-220. https://doi.org/10.1016/j.tourman.2007.07.016

[16] Song, H. and Witt, S.F. (2001) Forecasting Future Tourism Flows. Tour. Hosp. 21st Century, Butterworth-Heinemann, Oxford, 106-118.

[17] Li, G., Song, H. and Witt, S.F. (1993) Recent Developments in Econometric Modeling and Forecasting. Journal of Travel Research, 44, 82-99.

[18] Lim, C. and Mcaleer, M. (2001) Monthly Seasonal Variations: Asian Tourism to Australia. Annals of Tourism Research, 28, 68-82. https://doi.org/10.1016/S0160-7383(00)00002-5

[19] Papatheodorou, A. and Song, H. (2010) International Tourism Forecasts: Time-Series Analysis of World and Regional Data. Tourism Economics, 11, 11-23. https://doi.org/10.5367/0000000053297167

[20] Smeral, E. and Wuger, M. (2005) Does Complexity Matter? Methods for Improving Forecasting Accuracy in Tourism: The Case of Austria. Journal of Travel Research, 44, 100-110. https://doi.org/10.1177/0047287505276596

[21] Dritsakis, N. (2004) Cointegration Analysis of German and British Tourism Demand for Greece. Tourism Management, 25, 111-119. https://doi.org/10.1016/S0261-5177(03)00061-X

[22] Kulendran, N. and Wilson, K. (2000) Modelling Business Travel. Tourism Economics, 6, 47-59. https://doi.org/10.5367/000000000101297460

[23] Li, G., Wong, K.K.F., Song, H. and Witt, S.F. (2006) Tourism Demand Forecasting: A Time-Varying Parameter Error Correction Model. Journal of Travel Research, 45, 175-185. https://doi.org/10.1177/0047287506291596

[24] De Mello, M.M. and Nell, K.S. (2005) The Forecasting Ability of a Cointegrated VAR System of the UK Tourism Demand for France, Spain and Portugal. Empirical Economics, 30, 277-308. https://doi.org/10.1007/s00181-005-0241-0

[25] Divisekera, S. (2003) A Model of Demand for International Tourism. Annals of Tourism Research, 30, 31-49. https://doi.org/10.1016/S0160-7383(02)00029-4

[26] Durbarry, R. (2008) Tourism Taxes: Implications for Tourism Demand in the UK. Review of Development Economics, 12, 21-36. https://doi.org/10.1111/j.1467-9361.2008.00432.x

[27] Carey, K. (1991) Estimation of Caribbean Tourism Demand: Issues in Measurement and Methodology. Atlantic Economic Journal, 19, 32-44. https://doi.org/10.1007/BF02299101

[28] Lorde, T., Li, G. and Airey, D. (2015) Modeling Caribbean Tourism Demand: An Augmented Gravity Approach. Journal of Travel Research, 55, 946-956. 
https://doi.org/10.1177/0047287515592852

[29] Moore, W.R. (2010) The Impact of Climate Change on Caribbean Tourism Demand. Current Issues in Tourism, 13, 495-505. https://doi.org/10.1080/13683500903576045

[30] Lin, C.-T., Lee, I.-F. and Huang, Y.-L. (2009) Forecasting Thailand's Medical Tourism Demand and Revenue from Foreign Patients. Journal of Grey System, 4, 369-376.

[31] Hsu, L.-C. (2009) Forecasting the Output of Integrated Circuit Industry Using Genetic Algorithm Based Multivariable Grey Optimization Models. Expert Systems with Applications, 36, 7898-7903. https://doi.org/10.1016/j.eswa.2008.11.004

[32] Hsu, L.-C. (2003) Applying the Grey Prediction Model to the Global Integrated Circuit Industry. Technological Forecasting and Social Change, 70, 563-574. https://doi.org/10.1016/S0040-1625(02)00195-6

[33] Hsu, L.-C. (2011) Using Improved Grey Forecasting Models to Forecast the Output of Opto-Electronics Industry. Expert Systems with Applications, 38, 13879-13885. https://doi.org/10.1016/j.eswa.2011.04.192

[34] Guo, J.J., Wu, J.Y. and Wang, R.Z. (2011) A New Approach to Energy Consumption Prediction of Domestic Heat Pump Water Heater Based on Grey System Theory. Energy and Buildings, 43, 1273-1279. https://doi.org/10.1016/j.enbuild.2011.01.001

[35] Lee, S.-C. and Shih, L.-H. (2011) Forecasting of Electricity Costs Based on an Enhanced Grey-Based Learning Model: A Case Study of Renewable Energy in Taiwan. Technological Forecasting and Social Change, 78, 1242-1253. https://doi.org/10.1016/j.techfore.2011.02.009

[36] Hsu, C.-C. and Chen, C.-Y. (2003) Applications of Improved Grey Prediction Model for Power Demand Forecasting. Energy Conversion and Management, 44, 2241-2249. https://doi.org/10.1016/S0196-8904(02)00248-0

[37] Huang, K.Y. and Jane, C.-J. (2009) A Hybrid Model for Stock Market Forecasting and Portfolio Selection Based on ARX, Grey System and RS Theories. Expert Systems with Applications, 36, 5387-5392. https://doi.org/10.1016/j.eswa.2008.06.103

[38] Wang, Y. (2002) Predicting Stock Price Using Fuzzy Grey Prediction System. Expert Systems with Applications, 22, 33-38. https://doi.org/10.1016/S0957-4174(01)00047-1

[39] Wu, H. and Chen, F. (2011) The Application of Grey System Theory to Exchange Rate Prediction in the Post-Crisis Era. International Journal of Innovation Management, 2, 83-89.

[40] Hsu, C.L.P. and Chen, B. (2007) Comparing Accuracy of GM $(1,1)$ and Grey Verhulst Model in Taiwan Dental Clinics Forecasting. Journal of Grey System, 19, 31-38.

[41] Shen, X., Ou, L., Chen, X., Zhang, X. and Tan, X. (2013) The Application of the Grey Disaster Model to Forecast Epidemic Peaks of Typhoid and Paratyphoid Fever in China. PLoS ONE, 8, e60601. https://doi.org/10.1371/journal.pone.0060601

[42] Zhang, L., Zheng, Y., Wang, K., Zhang, X. and Zheng, Y. (2014) An Optimized Nash Nonlinear Grey Bernoulli Model Based on Particle Swarm Optimization and Its Application in Prediction for the Incidence of Hepatitis B in Xinjiang, China. Computers in Biology and Medicine, 49, 67-73.

[43] Liu, L., Wang, Q., Liu, M. and Li, L. (2014) An Intelligence Optimized Rolling Grey Forecasting Model Fitting to Small Economic Dataset. Abstract and Applied Analysis, 2014, 1-10. https://doi.org/10.1155/2014/641514

[44] Ma, D., Zhang, Q., Peng, Y. and Liu, S. (2011) A Particle Swarm Optimization 
Based Grey Forecast Model of Underground Pressure for Working Surface. Electronic Journal of Geotechnical Engineering, 16, 811-830.

[45] Wang, C.-H. and Hsu, L.-C. (2008) Using Genetic Algorithms Grey Theory to Forecast High Technology Industrial Output. Applied Mathematics and Computation, 195, 256-263. https://doi.org/10.1016/j.amc.2007.04.080

[46] Nguyen, N.T. and Tran, T.T. (2017) A Novel Integration of DEA, GM $(1,1)$ and Neural Network in Strategic Alliance for the Indian Electricity Organizations. Journal of Grey System, 29, 80-101.

[47] Thành, P.V. (2016) Enhanced Accuracy of Grey Forecasting Model Case by Tourism Industry in Vietnam. Hue University Journal of Science, 113, 157. https://doi.org/10.26459/jed.v113i14.3661

[48] Li, D.C., Yeh, C.W. and Chang, C.J. (2009) An Improved Grey-Based Approach for Early Manufacturing Data Forecasting. Computers \& Industrial Engineering, 57, 1161-1167. https://doi.org/10.1016/j.cie.2009.05.005

[49] Li, D.C. and Yeh, C.W. (2008) A Non-Parametric Learning Algorithm for Small Manufacturing Data Sets. Expert Systems with Applications, 34, 391-398. https://doi.org/10.1016/j.eswa.2006.09.008

[50] Hu, Y.C., Jiang, P. and Lee, P.C. (2018) Forecasting Tourism Demand by Incorporating Neural Networks into Grey-Markov Models. Journal of the Operational Research Society, 5682, 1-9. https://doi.org/10.1080/01605682.2018.1487821

[51] Liu, L., Wang, Q.R., Wang, J.Z. and Liu, M. (2016) A Rolling Grey Model Optimized by Particle Swarm Optimization in Economic Prediction. Computational Intelligence, 32, 391-419. https://doi.org/10.1111/coin.12059

[52] Lin, Z.S., Zhang, Q.S. and Liu, H. (2012) Parameter Optimization of GM $(1,1)$ Model Based on Artificial Fish Swarm Algorithm. Grey Systems: Theory and Application, 2, 166-177. https://doi.org/10.1108/20439371211260144

[53] Liu, S., Forrest, J. and Yang, Y. (2012) A Brief Introduction to Grey Systems Theory. Grey Systems: Theory and Application, 2, 89-104. https://doi.org/10.1108/20439371211260081

[54] Yan, Y., Liu, C., Qu, B., Zhao, Q. and Ji, F. (2011) Application of Grey Forecasting Model to Load Forecasting of Power System. Communications in Computer and Information Science, 244, 201-208.

[55] Tsai, C. (2012) The Application of Grey Theory to Taiwan Pollution Prediction. Proceedings of the World Congress on Engineering, 2, 2-7. 